\title{
A multicenter mixed-effects model for inference and prediction of 72-h return visits to the emergency department for adult patients with trauma-related diagnoses
}

\author{
Ehsan Yaghmaei ${ }^{1,2}$, Louis Ehwerhemuepha ${ }^{1,2^{*}}$ (D, William Feaster ${ }^{1}$, David Gibbs ${ }^{1}$ and Cyril Rakovski ${ }^{2}$
}

\begin{abstract}
Objective: Emergency department (ED) return visits within $72 \mathrm{~h}$ may be a sign of poor quality of care and entail unnecessary use of healthcare resources. In this study, we compare the performance of two leading statistical and machine learning classification algorithms, and we use the best performing approach to identify novel risk factors of ED return visits.
\end{abstract}

Methods: We analyzed 3.2 million ED encounters with at least one diagnosis under "injury, poisoning and certain other consequences of external causes" and "external causes of morbidity." These encounters included patients 18 years or older from across 128 emergency room facilities in the USA. For each encounter, we calculated the 72-h ED return status and retrieved 57 features from demographics, diagnoses, procedures, and medications administered during the process of administration of medical care. We implemented a mixed-effects model to assess the effects of the covariates while accounting for the hierarchical structure of the data. Additionally, we investigated the predictive accuracy of the extreme gradient boosting tree ensemble approach and compared the performance of the two methods.

Results: The mixed-effects model indicates that certain blunt force and non-blunt trauma inflates the risk of a return visit. Notably, patients with trauma to the head and patients with burns and corrosions have elevated risks. This is in addition to 11 other classes of both blunt force and non-blunt force traumas. In addition, prior healthcare resource utilization, patients who have had one or more prior return visits within the last 6 months, prior ED visits, and the number of hospitalizations within the 6 months are associated with increased risk of returning to the ED after discharge. On the one hand, the area under the receiver characteristic curve (AUROC) of the mixed-effects model was $0.710(0.707,0.712)$. On the other hand, the gradient boosting tree ensemble had a lower AUROC of $0.698 \mathrm{Cl}(0.696,0.700)$ on the independent test model.

(Continued on next page)

\footnotetext{
* Correspondence: lehwerhemuepha@choc.org

${ }^{1}$ CHOC Children's, Orange, CA 92868, USA

${ }^{2}$ Schmid College of Science \& Technology, Chapman University, Orange, CA, USA
}

(c) The Author(s). 2020 Open Access This article is licensed under a Creative Commons Attribution 4.0 International License, which permits use, sharing, adaptation, distribution and reproduction in any medium or format, as long as you give appropriate credit to the original author(s) and the source, provide a link to the Creative Commons licence, and indicate if changes were made. The images or other third party material in this article are included in the article's Creative Commons licence, unless indicated otherwise in a credit line to the material. If material is not included in the article's Creative Commons licence and your intended use is not permitted by statutory regulation or exceeds the permitted use, you will need to obtain permission directly from the copyright holder. To view a copy of this licence, visit http://creativecommons.org/licenses/by/4.0/ The Creative Commons Public Domain Dedication waiver (http://creativecommons.org/publicdomain/zero/1.0/) applies to the data made available in this article, unless otherwise stated in a credit line to the data. 


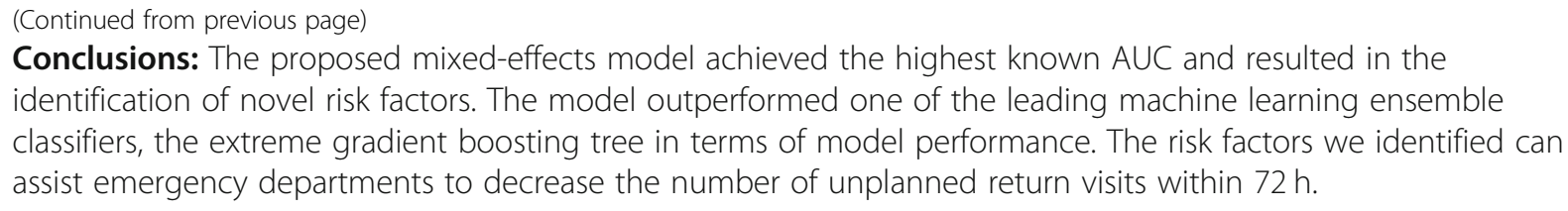

Keywords: Emergency department, Return visits, Trauma, Adult medicine

\section{Introduction}

Emergency departments across the USA are continually working on improving the quality of care as measured by health outcomes of patients, overall patient experience, and reduction in cost to both patients and facilities. These emergency department (ED) facilities are seeing annual increases in patient census that may impact the quality of care [1-3]. This increase in ED utilization is coupled with existing issues of overcrowding to exacerbate the challenges of providing a high quality of care and reducing both morbidity and mortality [4-11]. These challenges are complex and multifaceted and are further worsened by return visits to the ED that are avoidable. Consequently, the rate of return visits to the ED within $72 \mathrm{~h}$ of a previous discharge is being used as a metric for quality of care in the ED [1215]. Return visits to the ED may be reflective of poor quality of care but may also be caused by latent illnesses and misdiagnoses [16], unrelated new problems [17], perceived inability to access timely follow-up care, and patient uncertainty or fear about disease progression [18].

Patients with trauma/injuries have particularly high rates of potentially unnecessary return visits, with over $43.1 \%$ of corresponding revisits estimated as being avoidable in this group [12]. It is therefore important to understand and address the factors associated with return visits within this population. Several attempts have been made to address this issue, including studies focused on the role of patient demographics and socioeconomic status, mode of transportation, and level of trauma activation [19]. Further attempts have been made with a focus on patients with head injuries [20].

In this study, we specifically explored new variables in search of novel risk factors associated with ED returns for patients with trauma-related codes as captured by the International Classification of Diseases, Tenth Revision (ICD-10-CM) codes of S00-T79 (injury, poisoning and certain other consequences of external causes) and V00-Y99 (external causes of morbidity). There have been no comprehensive studies on the prediction of ED return visits among patients with trauma/injuries. Existing studies analyzed risk factors for presentation to the ED after the discharge of trauma patients from the hospital [21] and the effect of head trauma on risk of ED return within $72 \mathrm{~h}$ [20]. The objective of this study is to address this important problem and explore novel risk factors of ED revisits and design a corresponding prediction model. We compared the performance of advanced statistical methods and a high accuracy machine learning algorithm to determine the optimal classification model. We provide an assessment of model performance with recommendations on the potential implementation of the corresponding predictive models in the ED. The new variables we considered include several measures of current and past healthcare resource utilization that have been found to be associated with the related problem of hospital readmission [22-24].

\section{Methods}

This study was approved by CHOC Children's Hospital Institutional Review Board (IRB 180857).

\section{Study design and setting}

The data source for the study is the Cerner Health Facts database (referred to as Health Facts DB from here on). The Health Facts DB consists of data captured by the Cerner Corporation from over 100 US healthcare systems and over 650 facilities (in 2018) that is aggregated and organized into consumable datasets to facilitate research and reporting. It consists of clinical database tables that include information on ED visits, diagnoses, and medications. The descriptive and predictive multicenter models developed in this study were built using a subset of data from the database based on a priori inclusion criteria. An extensive analysis of a prior version of the database has been conducted with recommendations on its use [25].

\section{Selection of participants, measurements, and outcomes} We retrieved emergency department admission on patients 18 years or older from ED facilities in the USA from the Health Facts DB. We included EDs that contributed to the key database tables for the study (encounters, diagnoses, and medications tables) and have seen a large number of patients (set a priori at 10,000). These inclusion criteria ensured both the exclusion of potentially noisy data and the inclusion of large sample centers. We included multiple index encounters and revisits within $72 \mathrm{~h}$ for individual patients, and each 
encounter that was itself a revisit within $72 \mathrm{~h}$ was treated as an index encounter for estimating subsequent revisit to the ED. We included demographic variables as well as proxies for socioeconomic status, prior ED and hospital utilization variables, diagnoses, and the total number of medications administered during the ED visit.

\section{Analysis}

We categorized the ages of the patients based on the distribution of readmission rates by age, as shown in Fig. 1. We excluded very sparse variables (defined a priori as having less than 1000 responses) to prevent issues with statistical separation [26]. Sparse outcomes or analysis of rare events requires exact statistical tests [27].

We assessed multicollinearity by estimating the generalized variance inflation factor [28, 29] (GVIF) of the variables. In a stepwise process, we excluded the variable with the highest GVIF and reassessed multicollinearity until the GVIF of all variables kept is below 4-a rule of thumb threshold based on the previous studies [23]. We randomly split the data into two: $50 \%$ for model and the other $50 \%$ for evaluating model performance. We implemented a mixed-effects logistic regression model and gradient boosting tree ensemble [30, 31]. We conducted variable selection on the random intercept model using stepwise minimization of the Akaike Information Criteria and grid search for hyperparameter tuning on the gradient boosting algorithm. We assessed model performance using the area under the receiver operator characteristic curve (AUROC) and sensitivity and positive predictive value at a specificity of 0.90 . Analyses were carried out using Apache Spark [32, 33], the R Statistical Computing Programming Language [34], and Python [35].

\section{Results}

\section{Characteristics of study subjects}

A total of 128 ED facilities met the inclusion criteria resulting in 2.2 million patients and 3.2 encounters. Each facility contributed data from different periods of time between 2000 and 2017, and the average number of years of data from the facilities is 7.6 years with a standard deviation of 2.7 years. There were $64.8,23.8$, and $11.4 \%$ of patients with ages $18-49,50-69$, and 70 years or older, respectively. Note that the process of deidentification included a requirement to specify the age of patients older than 90 years as 90 to reduce the possibility of reidentification of patients by age. Patient sex consisted of $50.9 \%$ males, $49.0 \%$ females, and the remaining of unknown sex, while 68.3, 17.5, and 14.2\% were Caucasian, African American or Black, and other races and ethnicities. The overall rate of 72-h return visit to the ED is 0.037 .

There were 1.6 million encounters in the training dataset after splitting the data into two halves. In Tables 1 and 2, we provide the summary statistics on the training dataset, which includes all 57 variables we considered during model development. We excluded

\section{Age vs Proportion of ED Returns}

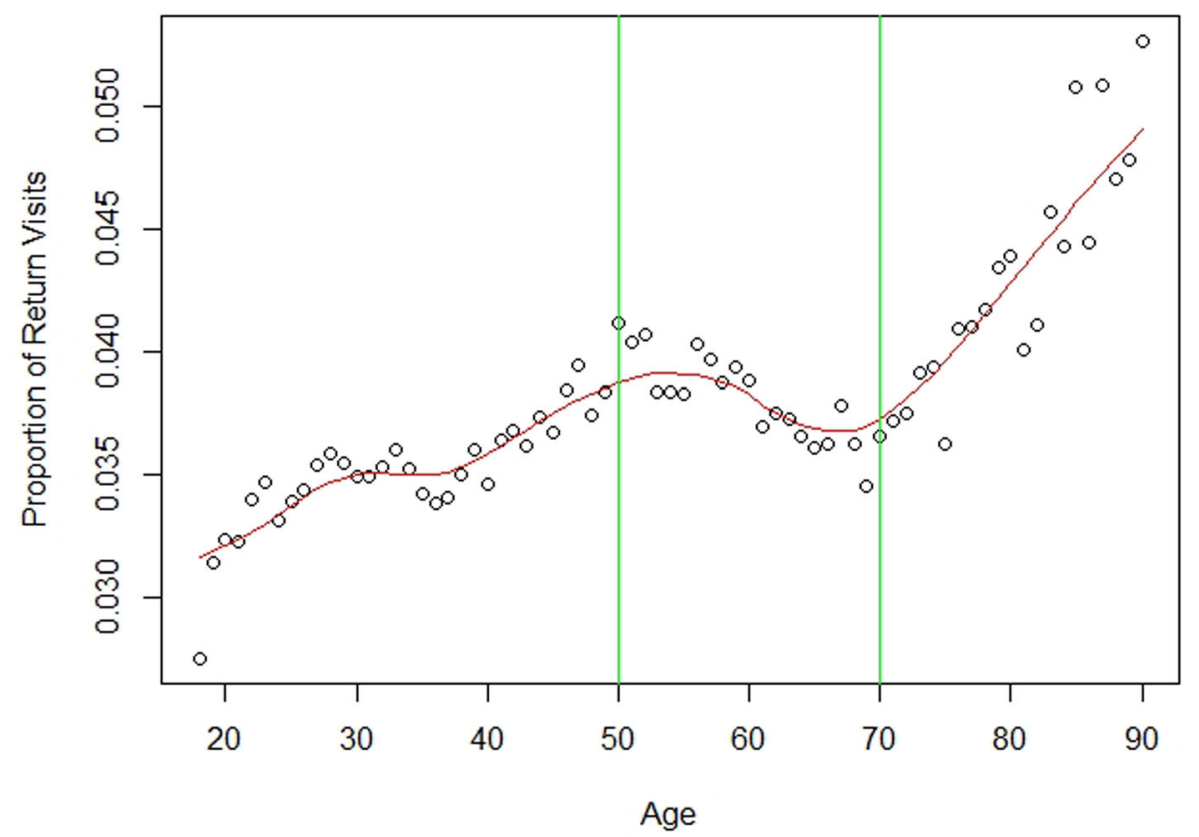

Fig. 1 Categorization of age. Age vs. proportion of ED returns 
Table 1 Summary statistics: demographics and trauma/injuries

\begin{tabular}{|c|c|c|c|c|}
\hline \multirow[t]{2}{*}{ Variable } & \multirow[t]{2}{*}{ Levels } & \multirow{2}{*}{$\begin{array}{l}\text { No return visit (72 h) } \\
n(\%) \text { or mean (sd) }\end{array}$} & \multirow{2}{*}{$\begin{array}{l}\text { Had a return visit (72 h) } \\
n(\%) \text { or mean (sd) }\end{array}$} & \multirow{2}{*}{$\begin{array}{l}p \text { value } \\
\text { (chi-squared } \\
\text { or } t \text { test) }\end{array}$} \\
\hline & & & & \\
\hline \multirow[t]{3}{*}{ Age, years } & $18-49$ & $985,654(64.96)$ & $35,628(61.55)$ & \multirow[t]{3}{*}{$<0.001$} \\
\hline & $50-69$ & $359,481(23.69)$ & $14,395(24.87)$ & \\
\hline & 70 or older & $172,214(11.35)$ & $7861(13.58)$ & \\
\hline \multirow[t]{6}{*}{ Race and/or ethnicity } & Caucasian & $1,037,221(68.36)$ & $38,904(67.21)$ & \multirow[t]{6}{*}{$<0.001$} \\
\hline & Hispanic & $31,535(2.08)$ & $964(1.67)$ & \\
\hline & Black & $266,147(17.54)$ & $10,178(17.58)$ & \\
\hline & Asian & $19,092(1.26)$ & $508(0.88)$ & \\
\hline & Native American & $43,271(2.85)$ & $3362(5.81)$ & \\
\hline & Other & $120,083(7.91)$ & $3968(6.86)$ & \\
\hline \multirow[t]{3}{*}{ Sex } & Female & $774,225(51.02)$ & $27,336(47.23)$ & \multirow[t]{3}{*}{$<0.001$} \\
\hline & Male & $741,267(48.85)$ & $30,518(52.72)$ & \\
\hline & Other/undisclosed & $1857(0.12)$ & $30(0.05)$ & \\
\hline \multirow[t]{3}{*}{ Length of stay (hours) } & 0 to 5 & $1,408,772(92.84)$ & $51,538(89.04)$ & \multirow[t]{3}{*}{$<0.001$} \\
\hline & 6 to 11 & $91,484(6.03)$ & $4905(8.47)$ & \\
\hline & 12 or more & $17,093(1.13)$ & $1441(2.49)$ & \\
\hline \multirow[t]{5}{*}{ Payer } & Commercial other & $487,429(32.12)$ & $16,044(27.72)$ & \multirow[t]{5}{*}{$<0.001$} \\
\hline & Medicare or Medicaid & $491,449(32.39)$ & $23,161(40.01)$ & \\
\hline & Other governmental & $57,319(3.78)$ & $2224(3.84)$ & \\
\hline & Self-pay & $267,644(17.64)$ & $10,080(17.41)$ & \\
\hline & Others & $213,508(14.07)$ & $6375(11.01)$ & \\
\hline \multirow[t]{4}{*}{ History of hospital visits } & 0 & $1,421,064(93.65)$ & $49,523(85.56)$ & \multirow[t]{4}{*}{$<0.001$} \\
\hline & 1 & $70,773(4.66)$ & $5155(8.91)$ & \\
\hline & 2 & $16,400(1.08)$ & $1712(2.96)$ & \\
\hline & 3 or more & $9112(0.60)$ & $1494(2.58)$ & \\
\hline \multirow{2}{*}{$\begin{array}{l}\text { Is index ED visit a revisit (within } 72 \mathrm{~h} \text { ) } \\
\text { of a previous encounter? }\end{array}$} & No & $1,463,245(96.43)$ & $50,429(87.12)$ & \multirow[t]{2}{*}{$<0.001$} \\
\hline & Yes & $54,104(3.57)$ & $7455(12.88)$ & \\
\hline \multirow[t]{4}{*}{ Previous ED visit } & 0 & $1,051,707(69.31)$ & $27,767(47.97)$ & \multirow[t]{4}{*}{$<0.001$} \\
\hline & 1 & $252,012(16.61)$ & $10,311(17.81)$ & \\
\hline & 2 & $95,731(6.31)$ & $5460(9.43)$ & \\
\hline & 3 or more & $117,899(7.77)$ & $14,346(24.78)$ & \\
\hline \multirow[t]{4}{*}{ History of return visits } & 0 & $1,459,191(96.17)$ & $47,481(82.03)$ & \multirow[t]{4}{*}{$<0.001$} \\
\hline & 1 & $39,372(2.59)$ & $4317(7.46)$ & \\
\hline & 2 & $9389(0.62)$ & $1829(3.16)$ & \\
\hline & 3 or more & $9397(0.62)$ & $4257(7.35)$ & \\
\hline \multirow[t]{2}{*}{ Number of medications } & Less than 4 & $1,423,293(93.80)$ & $52,342(90.43)$ & $<0.001$ \\
\hline & 4 or more & $94,056(6.20)$ & $5542(9.57)$ & \\
\hline Season & Winter & $324,662(21.40)$ & $12,281(21.22)$ & 0.003 \\
\hline & Spring & $364,282(24.01)$ & $13,878(23.98)$ & \\
\hline & Summer & $437,620(28.84)$ & $17,082(29.51)$ & \\
\hline & Fall & 390,785 (25.75) & $14,643(25.30)$ & \\
\hline Injuries and trauma & & & & \\
\hline Injuries to the head (S00-S09) & No & $1,178,863(77.69)$ & $42,170(72.85)$ & $<0.001$ \\
\hline & Yes & $338,486(22.31)$ & $15,714(27.15)$ & \\
\hline
\end{tabular}


Table 1 Summary statistics: demographics and trauma/injuries (Continued)

\begin{tabular}{|c|c|c|c|c|}
\hline \multirow[t]{2}{*}{ Variable } & \multirow[t]{2}{*}{ Levels } & \multirow{2}{*}{$\begin{array}{l}\text { No return visit }(72 \mathrm{~h}) \\
n(\%) \text { or mean }(\mathrm{sd})\end{array}$} & \multirow{2}{*}{$\begin{array}{l}\text { Had a return visit (72 h) } \\
n(\%) \text { or mean (sd) }\end{array}$} & \multirow{2}{*}{$\begin{array}{l}p \text { value } \\
\text { (chi-squared } \\
\text { or } t \text { test) }\end{array}$} \\
\hline & & & & \\
\hline \multirow[t]{2}{*}{ Injuries to the neck (S10-S19) } & No & $1,323,354(87.21)$ & $50,420(87.11)$ & \multirow[t]{2}{*}{0.442} \\
\hline & Yes & $193,995(12.79)$ & $7464(12.89)$ & \\
\hline \multirow[t]{2}{*}{ Injuries to the thorax (S20-\$29) } & No & $1,354,255(89.25)$ & $52,409(90.54)$ & \multirow[t]{2}{*}{$<0.001$} \\
\hline & Yes & $163,094(10.75)$ & $5475(9.46)$ & \\
\hline \multirow{2}{*}{$\begin{array}{l}\text { Injuries to the abdomen, lower back, lumbar } \\
\text { spine, pelvis, and external genitals (S30-S39) }\end{array}$} & No & $1,336,251(88.06)$ & $51,054(88.20)$ & \multirow[t]{2}{*}{0.326} \\
\hline & Yes & $181,098(11.94)$ & $6830(11.80)$ & \\
\hline \multirow[t]{2}{*}{ Injuries to the shoulder and upper arm (S40-S49) } & No & $1,380,266(90.97)$ & $53,145(91.81)$ & \multirow[t]{2}{*}{$<0.001$} \\
\hline & Yes & $137,083(9.03)$ & $4739(8.19)$ & \\
\hline \multirow[t]{2}{*}{ Injuries to the elbow and forearm (S50-S59) } & No & $1,418,621(93.49)$ & $53,603(92.60)$ & \multirow[t]{2}{*}{$<0.001$} \\
\hline & Yes & $98,728(6.51)$ & $4281(7.40)$ & \\
\hline \multirow[t]{2}{*}{ Injuries to the wrist, hand, and fingers (S60-S69) } & No & $1,242,857(81.91)$ & $47,690(82.39)$ & \multirow[t]{2}{*}{0.003} \\
\hline & Yes & $274,492(18.09)$ & $10,194(17.61)$ & \\
\hline \multirow[t]{2}{*}{ Injuries to the hip and thigh (S70-S79) } & No & $1,438,356(94.79)$ & $54,311(93.83)$ & \multirow[t]{2}{*}{$<0.001$} \\
\hline & Yes & $78,993(5.21)$ & $3573(6.17)$ & \\
\hline \multirow[t]{2}{*}{ Injuries to the knee and lower leg (S80-S89) } & No & $1,297,862(85.53)$ & $50,337(86.96)$ & \multirow[t]{2}{*}{$<0.001$} \\
\hline & Yes & $219,487(14.47)$ & $7547(13.04)$ & \\
\hline \multirow[t]{2}{*}{ Injuries involving multiple body regions(T07) } & No & $1,467,511(96.72)$ & $55,833(96.46)$ & \multirow[t]{2}{*}{$<0.001$} \\
\hline & Yes & $49,838(3.28)$ & $2051(3.54)$ & \\
\hline \multirow[t]{2}{*}{ Injury of unspecified body region (T14-T14) } & No & $1,438,869(94.83)$ & $54,732(94.55)$ & \multirow[t]{2}{*}{0.004} \\
\hline & Yes & $78,480(5.17)$ & $3152(5.45)$ & \\
\hline \multirow{2}{*}{$\begin{array}{l}\text { Effects of foreign body entering through natural } \\
\text { orifice (T15-T19) }\end{array}$} & No & $1,491,654(98.31)$ & $57,218(98.85)$ & \multirow[t]{2}{*}{$<0.001$} \\
\hline & Yes & $25,695(1.69)$ & $666(1.15)$ & \\
\hline \multirow[t]{2}{*}{ Burns and corrosions (T20-T32) } & No & $1,495,027(98.53)$ & $56,775(98.08)$ & \multirow[t]{2}{*}{$<0.001$} \\
\hline & Yes & $22,322(1.47)$ & 1109 (1.92) & \\
\hline Poisoning by, adverse effect of, and underdosing of & No & $1,478,655(97.45)$ & $55,611(96.07)$ & $<0.001$ \\
\hline & Yes & $38,694(2.55)$ & $2273(3.93)$ & \\
\hline Toxic effects of substances chiefly nonmedicinal & No & $1,494,884(98.52)$ & $56,899(98.30)$ & $<0.001$ \\
\hline & Yes & $22,465(1.48)$ & $985(1.70)$ & \\
\hline Other and unspecified effects of external causes (T66-T78) & No & $1,459,709(96.20)$ & $54,995(95.01)$ & $<0.001$ \\
\hline & Yes & $57,640(3.80)$ & $2889(4.99)$ & \\
\hline Complications of surgical and medical care, not & No & $1,488,928(98.13)$ & $55,404(95.72)$ & $<0.001$ \\
\hline & Yes & $28,421(1.87)$ & $2480(4.28)$ & \\
\hline Injuries to the ankle and foot (\$90-\$99) & No & $1,289,905(85.01)$ & $50,655(87.51)$ & $<0.001$ \\
\hline & Yes & 227,444 (14.99) & 7229 (12.49) & \\
\hline
\end{tabular}

variables capturing surgical procedures on the endocrine, hemic/lymphatic, and mediastinum/diaphragm systems due to sparsity and potential problems with statistical separation and multicollinearity.

\section{Main results}

Our results indicate that the highest risk factors attributable to the type of trauma/injuries include certain early complications of trauma such as embolisms and traumatic compartment syndrome (ICD $10 \mathrm{CM}$ : T79); burns and corrosions (T20-T32); certain effects of external causes such as hypothermia, asphyxiation, and abuse (T66-T78); poisoning due to medical and biological substances (T36T50); and injuries to the head (S00-S09). Patients with early complications of trauma have $120 \%$ increase in odds of return visit; patients with burns and corrosions, effects of external causes (such as hypothermia, asphyxiation, and abuse), poisoning, and injuries to the head have an 
Table 2 Summary statistics: other diagnoses/comorbidities and surgical procedures

\begin{tabular}{|c|c|c|c|c|}
\hline \multirow[t]{2}{*}{ Variable } & \multirow[t]{2}{*}{ Levels } & \multirow{2}{*}{$\begin{array}{l}\text { No return visit (72 h) } \\
n(\%) \text { or mean (sd) }\end{array}$} & \multirow{2}{*}{$\begin{array}{l}\text { Had a return visit (72 h) } \\
n(\%) \text { or mean (sd) }\end{array}$} & \multirow{2}{*}{$\begin{array}{l}p \text { value } \\
\text { (chi-squared } \\
\text { or } t \text { test) }\end{array}$} \\
\hline & & & & \\
\hline \multicolumn{5}{|l|}{ Other diagnoses/comorbidities } \\
\hline \multirow[t]{2}{*}{ Certain infectious and parasitic diseases (A00-B99) } & No & $1,501,709(98.97)$ & $57,020(98.51)$ & $<0.001$ \\
\hline & Yes & $15,640(1.03)$ & $864(1.49)$ & \\
\hline \multirow[t]{2}{*}{ Neoplasms (C00-D49) (excluding encounters for chemotherapy) } & No & $1,510,526(99.55)$ & $57,523(99.38)$ & $<0.001$ \\
\hline & Yes & $6823(0.45)$ & $361(0.62)$ & \\
\hline \multirow{2}{*}{$\begin{array}{l}\text { Diseases of the blood and blood-forming organs and certain } \\
\text { disorders involving the immune mechanism (D50-D89) }\end{array}$} & No & $1,504,241(99.14)$ & $57,041(98.54)$ & $<0.001$ \\
\hline & Yes & $13,108(0.86)$ & $843(1.46)$ & \\
\hline \multirow[t]{2}{*}{ Endocrine, nutritional, and metabolic diseases (E00-E89) } & No & $1,376,422(90.71)$ & $51,121(88.32)$ & $<0.001$ \\
\hline & Yes & $140,927(9.29)$ & $6763(11.68)$ & \\
\hline \multirow[t]{2}{*}{ Mental, behavioral, and neurodevelopmental disorders (F01-F99) } & No & $1,296,066(85.42)$ & $45,219(78.12)$ & $<0.001$ \\
\hline & Yes & $221,283(14.58)$ & $12,665(21.88)$ & \\
\hline \multirow[t]{2}{*}{ Disease of the nervous system (G00-G99) } & No & $1,417,394(93.41)$ & $52,214(90.20)$ & $<0.001$ \\
\hline & Yes & $99,955(6.59)$ & $5670(9.80)$ & \\
\hline \multirow[t]{2}{*}{ Diseases of the eye and adnexa ( $\mathrm{H} 00-\mathrm{H} 59)$} & No & $1,474,791(97.20)$ & $56,370(97.38)$ & 0.007 \\
\hline & Yes & $42,558(2.80)$ & $1514(2.62)$ & \\
\hline \multirow[t]{2}{*}{ Diseases of the circulatory system (100-199) } & No & $1,330,196(87.67)$ & $48,567(83.90)$ & $<0.001$ \\
\hline & Yes & $187,153(12.33)$ & $9317(16.10)$ & \\
\hline \multirow[t]{2}{*}{ Diseases of the respiratory system (J00-J99) } & No & $1,449,050(95.50)$ & $54,362(93.92)$ & $<0.001$ \\
\hline & Yes & $68,299(4.50)$ & $3522(6.08)$ & \\
\hline \multirow[t]{2}{*}{ Diseases of the digestive system (K00-K95) } & No & $1,453,950(95.82)$ & $54,637(94.39)$ & $<0.001$ \\
\hline & Yes & $63,399(4.18)$ & $3247(5.61)$ & \\
\hline \multirow[t]{2}{*}{ Diseases of the skin and subcutaneous tissue (L00-L99) } & No & $1,456,934(96.02)$ & $53,432(92.31)$ & $<0.001$ \\
\hline & Yes & $60,415(3.98)$ & $4452(7.69)$ & \\
\hline \multirow{2}{*}{$\begin{array}{l}\text { Diseases of the musculoskeletal system and } \\
\text { connective tissue (M00-M99) }\end{array}$} & No & $963,184(63.48)$ & $39,179(67.69)$ & $<0.001$ \\
\hline & Yes & $554,165(36.52)$ & $18,705(32.31)$ & \\
\hline \multirow[t]{2}{*}{ Disease of the genitourinary system (N00-N99) } & No & $1,433,691(94.49)$ & $53,793(92.93)$ & $<0.001$ \\
\hline & Yes & $83,658(5.51)$ & $4091(7.07)$ & \\
\hline \multirow[t]{2}{*}{ Pregnancy, childbirth, and the puerperium (O00-O9A) } & No & $1,508,641(99.43)$ & $57,549(99.42)$ & 0.902 \\
\hline & Yes & $8708(0.57)$ & $335(0.58)$ & \\
\hline \multirow{2}{*}{$\begin{array}{l}\text { Congenital malformations, deformations, and chromosomal } \\
\text { abnormalities (Q00-Q99) }\end{array}$} & No & $1,514,720(99.83)$ & $57,788(99.83)$ & 0.711 \\
\hline & Yes & $2629(0.17)$ & $96(0.17)$ & \\
\hline \multirow{2}{*}{$\begin{array}{l}\text { Symptoms, signs, and abnormal clinical and laboratory } \\
\text { findings, not elsewhere classified (R00-R99) }\end{array}$} & No & $1,210,410(79.77)$ & $42,401(73.25)$ & $<0.001$ \\
\hline & Yes & $306,939(20.23)$ & $15,483(26.75)$ & \\
\hline \multirow[t]{2}{*}{ External causes of morbidity (V00-Y99) } & No & $389,533(25.67)$ & $15,725(27.17)$ & $<0.001$ \\
\hline & Yes & $1,127,816(74.33)$ & $42,159(72.83)$ & \\
\hline \multirow{2}{*}{$\begin{array}{l}\text { Factors influencing health status and contact with } \\
\text { health services (Z00-Z99) }\end{array}$} & No & $1,198,725(79.00)$ & $42,590(73.58)$ & $<0.001$ \\
\hline & Yes & $318,624(21.00)$ & $15,294(26.42)$ & \\
\hline Surgical procedures & & & & \\
\hline Integumentary surgery (CPT4: 10030-19499) & No & $1,425,628(93.96)$ & $53,469(92.37)$ & $<0.001$ \\
\hline & Yes & $91,721(6.04)$ & $4415(7.63)$ & \\
\hline Musculoskeletal surgery (CPT4: 20100-29999) & No & $1,460,822(96.27)$ & $56,089(96.90)$ & $<0.001$ \\
\hline & Yes & $56,527(3.73)$ & $1795(3.10)$ & \\
\hline Respiratory surgery (CPT4: 30000-32999) & No & $1,516,932(99.97)$ & $57,790(99.84)$ & $<0.001$ \\
\hline
\end{tabular}


Table 2 Summary statistics: other diagnoses/comorbidities and surgical procedures (Continued)

\begin{tabular}{|c|c|c|c|c|}
\hline \multirow[t]{2}{*}{ Variable } & \multirow[t]{2}{*}{ Levels } & \multirow{2}{*}{$\begin{array}{l}\text { No return visit (72 h) } \\
n(\%) \text { or mean (sd) }\end{array}$} & \multirow{2}{*}{$\begin{array}{l}\text { Had a return visit (72 h) } \\
n(\%) \text { or mean (sd) }\end{array}$} & \multirow{2}{*}{$\begin{array}{l}p \text { value } \\
\text { (chi-squared } \\
\text { or } t \text { test) }\end{array}$} \\
\hline & & & & \\
\hline & Yes & $417(0.03)$ & $94(0.16)$ & \\
\hline \multirow[t]{2}{*}{ Cardiovascular surgery (CPT4: 33010-37799) } & No & $1,495,828(98.58)$ & $56,739(98.02)$ & $<0.001$ \\
\hline & Yes & $21,521(1.42)$ & $1145(1.98)$ & \\
\hline \multirow[t]{2}{*}{ Digestive surgery (CPT4: 40490-49999) } & No & $1,512,836(99.70)$ & $57,767(99.80)$ & $<0.001$ \\
\hline & Yes & $4513(0.30)$ & $117(0.20)$ & \\
\hline \multirow[t]{2}{*}{ Urinary/reproductive system surgery (CPT4: 50010-58999) } & No & $1,515,308(99.87)$ & $57,740(99.75)$ & $<0.001$ \\
\hline & Yes & $2041(0.13)$ & $144(0.25)$ & \\
\hline \multirow[t]{2}{*}{ Nervous system surgery (CPT4: 61000-64999) } & No & $1,515,677(99.89)$ & $57,798(99.85)$ & 0.008 \\
\hline & Yes & $1672(0.11)$ & $86(0.15)$ & \\
\hline \multirow[t]{2}{*}{ Eye/ocular surgery (CPT4: 65091-68899) } & No & $1,515,061(99.85)$ & $57,833(99.91)$ & $<0.001$ \\
\hline & Yes & $2288(0.15)$ & $51(0.09)$ & \\
\hline \multirow[t]{2}{*}{ Auditory surgery (CPT4: 69000-69979) } & No & $1,516,050(99.91)$ & $57,867(99.97)$ & $<0.001$ \\
\hline & Yes & $1299(0.09)$ & $17(0.03)$ & \\
\hline
\end{tabular}

increase in odds of $55,54,35$, and $29 \%$ respectively. We found eight additional categories associated with increased odds of a return visit. Patients suffering from the toxic effects of nonmedicinal sources such as alcohol, carbon monoxide, and venom (T51-T65) have a $27 \%$ increase in odds of a return visit. The remaining risk factors were all blunt force traumas such as injuries to the elbow and forearm (S50-S59); injuries to the wrist, hand, and fingers (S60-S69); and injuries to the hip and thigh (S70-S79). Other trauma-related risk factors (attributable to blunt forces) are shown in Table 3 with corresponding odds ratios and $95 \%$ confidence interval.

We also found that certain injuries/traumas are associated with reduced odds of a return visit. Injuries to the shoulder and upper arm (S40-S49), injuries to the ankle and foot (S90-S99), injuries to the thorax (S20-S29), and effects of foreign body entering through natural orifice (T15-T19) have 5, 5, 8, and $14 \%$ decrease in the odds of a return visit. The effect of other trauma variables not captured in Table 2 did not achieve statistical significance.

In addition to these findings on patient demographics, proxies for socioeconomic status, proxies for healthcare utilizations, and certain comorbidities were associated with the risk of a return visit. Older patients have increased odds of a return visit. There is a $20 \%$ increase in odds of return visits for male patients compared to female patients. African American/Black patients, as well as patients of Hispanic origins, have 5 and 13\% drop in the odds of a return visit compared to Caucasians. Patients with health insurance type other than commercial have increased odds of a return visit. Compared to patients discharged from the ED within the first hour, patients with ED length of stay between 1 and $12 \mathrm{~h}$ and those with greater than $12 \mathrm{~h}$ length of stay have 35 and $74 \%$ increase in odds of a return visit. The number of previous hospitalizations, previous ED visits, and previous return visits to the ED within the last 6 months were all risk factors of a subsequent return visit to the ED. Patients with previous hospitalizations have 26 to $61 \%$ increase in odds, those with previous ED visits have 30 to $114 \%$ increase in odds, and those with previous return visits have 38 to $301 \%$ increase in odds of a subsequent return visit. Furthermore, when a patient experiences a return visit and is discharged home, the odds of a subsequent return visit increases by $50 \%$.

Lastly, patients with comorbidities relating to the circulatory system (I00-199), the nervous (G00-G99) systems, or arising from complications of surgical and medical care (T80-T88) have 3, 9 and 36\% increase in the odds of a return visit respectively.

The AUROC of the mixed-effects model was 0.710 $(0.707,0.712)$, while the AUROC of the gradient boosting tree ensemble (the machine learning algorithm) was lower at $0.698 \mathrm{CI}(0.696,0.700)$. In Table 4 , we express the performance of the model at specificities between 55 and $95 \%$ inclusive. We suggest three risk strata: high risk for patients with predicted probabilities greater than 0.0604 (nearly twice the overall rate of return visits), moderate-risk patients with predicted probabilities between 0.0417 and 0.0604 , and low-risk patients with predicted probabilities less than 0.0417 (just slightly higher than the baseline risk). We expect over $50 \%$ of all at-risk patients (for return visits to the ED within $72 \mathrm{~h}$ ) to be captured in the high and moderate risk strata with an overall number needed to evaluate (NNE) of 12. 
Table 3 Multivariable model

\begin{tabular}{|c|c|c|c|}
\hline Variables & Levels & OR $(95 \% \mathrm{Cl})$ & $p$ value \\
\hline \multicolumn{4}{|l|}{ Injuries/trauma } \\
\hline Certain early complications of trauma (T79) & - & $2.221(1.998,2.468)$ & $<0.001$ \\
\hline Burns and corrosions (T20-T32) & - & $1.550(1.454,1.651)$ & $<0.001$ \\
\hline Other and unspecified effects of external causes (T66-T78) & - & $1.547(1.484,1.613)$ & $<0.001$ \\
\hline $\begin{array}{l}\text { Poisoning by, adverse effect of, and underdosing of drugs, } \\
\text { medicaments, and biological substances (T36-T50) }\end{array}$ & - & $1.350(1.287,1.416)$ & $<0.001$ \\
\hline Injuries to the head (S00-S09) & - & $1.286(1.258,1.316)$ & $<0.001$ \\
\hline Toxic effects of substances chiefly nonmedicinal as to source (T51-T65) & - & $1.274(1.191,1.362)$ & $<0.001$ \\
\hline Injuries to the elbow and forearm (S50-S59) & - & $1.203(1.163,1.245)$ & $<0.001$ \\
\hline Injuries to the wrist, hand, and fingers (S60-S69) & - & $1.180(1.151,1.209)$ & $<0.001$ \\
\hline Injuries to the hip and thigh (S70-S79) & - & $1.139(1.098,1.182)$ & $<0.001$ \\
\hline Injuries involving multiple body regions (T07) & - & $1.071(1.022,1.123)$ & 0.004 \\
\hline Injury of unspecified body region (T14-T14) & - & $1.062(1.023,1.104)$ & 0.002 \\
\hline $\begin{array}{l}\text { Injuries to the abdomen, lower back, lumbar spine, pelvis, } \\
\text { and external genitals (S30-S39) }\end{array}$ & - & $1.038(1.010,1.068)$ & 0.008 \\
\hline Injuries to the knee and lower leg (S80-S89) & - & $1.035(1.006,1.066)$ & 0.018 \\
\hline Injuries to the shoulder and upper arm (S40-S49) & - & $0.951(0.921,0.981)$ & 0.002 \\
\hline Injuries to the ankle and foot (\$90-\$99) & - & $0.947(0.919,0.975)$ & $<0.001$ \\
\hline Injuries to the thorax (S20-S29) & - & $0.923(0.895,0.951)$ & $<0.001$ \\
\hline Effects of foreign body entering through natural orifice (T15-T19) & - & $0.866(0.800,0.938)$ & $<0.001$ \\
\hline \multicolumn{4}{|l|}{ Demographics, SES, and healthcare utilization } \\
\hline \multirow[t]{3}{*}{ Length of stay, hours } & {$[0,1)$} & Ref & $<0.001$ \\
\hline & {$[1,12)$} & $1.352(1.308,1.398)$ & \\
\hline & 12 or more & $1.742(1.638,1.852)$ & \\
\hline \multirow[t]{5}{*}{ Payer } & Commercial & Ref & $<0.001$ \\
\hline & Medicare/Medicaid & $1.283(1.252,1.314)$ & \\
\hline & Other governmental & $1.188(1.131,1.247)$ & \\
\hline & Self-pay & $1.225(1.191,1.259)$ & \\
\hline & Others & $1.176(1.137,1.216)$ & \\
\hline \multirow[t]{3}{*}{ Age (years) } & {$[0,50)$} & Ref & \\
\hline & {$[5070)$} & $1.025(1.003,1.047)$ & 0.024 \\
\hline & [70 or older) & $1.125(1.092,1.159)$ & $<0.001$ \\
\hline \multirow[t]{6}{*}{ Race/ethnicity } & Caucasian & Ref & \\
\hline & Hispanic & $0.873(0.815,0.935)$ & $<0.001$ \\
\hline & African American/Black & $0.946(0.922,0.971)$ & $<0.001$ \\
\hline & Asian/Pacific Islander & $0.916(0.836,1.004)$ & 0.062 \\
\hline & Native American & $1.036(0.974,1.101)$ & 0.262 \\
\hline & Others/Unknown & $0.902(0.870,0.935)$ & $<0.001$ \\
\hline \multirow[t]{3}{*}{ Sex } & Female & Ref & \\
\hline & Male & $1.198(1.177,1.219)$ & $<0.001$ \\
\hline & Others/known & $0.888(0.606,1.300)$ & 0.541 \\
\hline \multirow[t]{4}{*}{ Previous hospitalization (prior 6 months) } & 0 & Ref & $<0.001$ \\
\hline & 1 & $1.263(1.223,1.305)$ & \\
\hline & 2 & $1.369(1.295,1.448)$ & \\
\hline & 3 or more & $1.61(1.512,1.715)$ & \\
\hline
\end{tabular}


Table 3 Multivariable model (Continued)

\begin{tabular}{|c|c|c|c|}
\hline Variables & Levels & OR $(95 \% \mathrm{Cl})$ & $p$ value \\
\hline Index ED visit is itself a return visit & Yes & $1.505(1.46,1.551)$ & $<0.001$ \\
\hline \multirow[t]{4}{*}{ Number of previous ED visits (prior 6 months) } & 0 & Ref & \multirow[t]{4}{*}{$<0.001$} \\
\hline & 1 & $1.301(1.27,1.333)$ & \\
\hline & 2 & $1.655(1.603,1.708)$ & \\
\hline & 3 or more & $2.145(2.078,2.214)$ & \\
\hline \multirow[t]{4}{*}{ Number of previous return visits (prior 6 months) } & 0 & Ref & \multirow[t]{4}{*}{$<0.001$} \\
\hline & 1 & $1.38(1.326,1.436)$ & \\
\hline & 2 & $2.012(1.897,2.135)$ & \\
\hline & 3 or more & $4.014(3.825,4.213)$ & \\
\hline \multicolumn{4}{|l|}{ Diagnoses/comorbidities } \\
\hline Diseases of the circulatory system (100-199) & - & $1.032(1.005,1.060)$ & 0.020 \\
\hline Disease of the nervous system (G00-G99) & - & $1.085(1.052,1.118)$ & $<0.001$ \\
\hline $\begin{array}{l}\text { Complications of surgical and medical care, not } \\
\text { elsewhere classified (T80-T88) }\end{array}$ & - & $1.364(1.301,1.43)$ & $<0.001$ \\
\hline
\end{tabular}

\section{Limitations}

There are, however, some limitations in the data/database used. Proper analyses of the reasons patients return to the ED were not considered given the multi-center nature of the dataset, the absence of clinical notes, and the large sample sizes. We relied on diagnostic codes often riddled with data entry errors and inconsistency of use between providers and institutions. These limitations have a lesser impact as the size of the overall dataset increases. Consequently, we believe that these limitations may have a negligible impact on inference as a result of the very large sample sizes used. Furthermore, variations in clinical care across different EDs in the USA are compensated for using a mixed-effects model with the EDs as random intercepts.

\section{Discussion/conclusion}

ED return visits within $72 \mathrm{~h}$ of discharge in adults may be a result of poor quality of care, poor patient education on the use of ED, poor social determinants of health, and complex psychological/psychosocial influences. The underlying causal factors for these return visits have not been formally established, so we rely on statistical associations in order to better identify high-risk patients. In some cases, return visits are unpreventable, such as a patient returning for reasons unrelated to the initial visit, unforeseen deterioration of health unrelated to the quality of care received during the initial visit, and patient misuse of the ED, among others [16-18, 21]. But identification of factors associated with high risk of return visits may help in the identification of high-risk patients for targeted intervention, especially in the presence of scarce and expensive clinical resources for such interventions. In this study, we used mixed-effects regression to explore new variables in search of novel risk factors associated with ED returns for adult patients visiting the ED for trauma (or trauma-related conditions). We assessed the effect of the type of trauma, demographics, and proxies for socioeconomic status, prior ED and hospital utilization variables, diagnoses, and the total number of medications administered during the ED visit.

Table 4 Model performance

\begin{tabular}{|c|c|c|c|c|c|}
\hline Specificity (\%) & Predicted probability threshold & Sensitivity (\%) & PPV & NNE & Risk Strata \\
\hline 95 & 0.0844 & $24.7(24.4,25.1)$ & $15.9(15.6,16.1)$ & 7 & High \\
\hline 90 & 0.0604 & $36.3(35.9,36.7)$ & $12.2(12.0,12.3)$ & 9 & \\
\hline 85 & 0.0489 & $44.5(44.1,44.9)$ & $10.2(10.0,10.3)$ & 10 & Moderate \\
\hline 80 & 0.0417 & $50.9(50.5,51.3)$ & $8.9(8.8,9.0)$ & 12 & \\
\hline 75 & 0.0368 & $56.2(55.8,56.6)$ & $7.9(7.8,8.0)$ & 13 & Low \\
\hline 70 & 0.0333 & $60.9(60.5,61.3)$ & $7.2(7.1,7.3)$ & 14 & \\
\hline 65 & 0.0307 & $65.1(64.7,65.5)$ & $6.6(6.6,6.7)$ & 16 & \\
\hline 60 & 0.0286 & $69.0(68.7,69.4)$ & $6.2(6.1,6.2)$ & 17 & \\
\hline 55 & 0.0268 & $72.7(72.4,73.1)$ & $5.8(5.8,5.9)$ & 18 & \\
\hline
\end{tabular}


Our results indicate that both non-blunt and blunt traumas to certain regions of the body are associated with increased odds of a return visit to the ED. The non-blunt traumas include early complications of trauma (such as air/fat embolism, traumatic shock, and traumatic compartment syndrome), burns and corrosions, trauma due to external causes such as hypothermia or asphyxiation, and poisoning resulting by medicaments and biological substances. Factors such as poisoning/adverse effects of medications and nonmedicinal sources and trauma due to external causes (such as hypothermia and asphyxiation) may require a more strategic approach to be impactful.

Blunt traumas to certain body regions of the head, hand, knee, legs, and abdomen/lower back/external genitals were associated with increased odds of a return visit. On the one hand, injuries to the head are often serious and/or alarming due to the potential for death, traumatic brain injury, concussion, and post-concussive syndrome. The gravity or morbidity associated with head injuries may result in higher odds for return visits among patients discharged home. Potential improvement in the quality of care and post-discharge follow-up of patients with head injuries may be achieved with a model such as the mixed-effects model we developed here by careful design of intervention protocols on the discharge education of patients with head injuries. On the other hand, injuries to the hand and regions of the legs may impede mobility and dexterity and are easy to aggravate in the attempt to return to routine daily activities. This is a case where education of patients on the need for rest as well as the risk of a return visit may be helpful. Regardless of the cause, patients with these risk factors may benefit the most from education, social services interventions, and interventions aimed at ameliorating the effects of poor social determinants of health. We note that misdiagnosis captured and left uncorrected in the EMR would be captured in the data used for the study. But the size of the data would guarantee that misdiagnoses are ignorable noise in the study.

The result on prior healthcare utilization variables indicates that patients who may be suffering from complex chronic conditions and/or who have easier access to the healthcare system have higher odds of a return to the ED after the index visit. Patients with chronic conditions are likely to be more educated about the healthcare system (due to frequent utilization), and their return visits are expected to be due to exacerbation of health and unexpected complications due to underlying conditions. These patients are likely to have the highest proportion of unpreventable revisits within $72 \mathrm{~h}$. But this also calls to question the proper management of their chronic conditions and the role of primary care physicians in chronic disease management.
Results on demographics and social determinants indicate that patients from higher socioeconomic families (as captured by health insurance type) have a higher risk of a return visit. While the reason for this association is not clear, we surmise that the use of the ED may be associated with having the means to pay, to be transported, and to spend time away from work or other daily activities. This means that there may be challenges to access of care of patients from lower socioeconomic status. We found a sex difference in the risk of returning to the ED with male patients more likely to have a return visit as well as older patients (compared to their younger peers). The result on difference in sex is expected under the assumption that male patients are more likely to engage in physical (or more physically strenuous) activities that may result in exacerbation of injuries. The result on difference in risk due to age (with older patients more likely to return to the ED) does not lend itself to easy explanations even though we expect that older patients have more complex conditions. We would also expect that older patients are more likely to be admitted to the hospital from the ED, and more care may be taken by providers before discharge home directly from the ED.

The mixed-effects model can be used to rank patients on the predicted probability of returning after discharge. Patients who rank most at-risk for a return visit can be intervened on in any number of the following ways. First, identified risk factors may guide more detailed evaluation of the patient at the initial encounter. Second, additional discharge instructions may be provided based on patient conditions, factors that may result in deterioration of health after discharge, and more detailed postdischarge plans to mitigate unnecessary utilization of the ED. Third, the pre-discharge discussion may facilitate the transition to primary care providers and identify those patients who do not have adequate primary care access. Fourth, proper post-discharge phone calls in cases where appropriate may resolve many issues without unneeded visits while identifying those who need prompt reassessment. These four intervention opportunities are expensive on resources, but targeted interventions based on patients the model predicts to be most at-risk may provide the most impact in the improvement of the overall care of patients.

These risk factors, coupled with the high predictive power of the mixed-effects model (as measured by its AUROC of 0.710), indicate that the model may possess strong clinical utility. The mixed-effects model performed better than the machine learning model, most likely due to the appropriateness of a mixed-effects model in this data/study settings. Most studies on ED return visits have low model performance due to the complexity of reasons for return visits (which may include non- 
clinical factors not captured in the EMR). Consequently, attention should be paid to the novel variables used in the model in an attempt to improve on existing models. Our findings include novel variables on the type of trauma as well as various patterns of past healthcare utilization. We believe that this model would serve great clinical utility and may help in the identification of proper intervention protocols to reducing unnecessary utilization of the ED. We believe it is of importance in 3 ways: (1) as a simple indication that there are simple risk factors (certain type of traumas) for which the risk of a return visit is high. This informs the ER provider, but the result is a long list that we would not expect providers to memorize among all the important facets for patient care. (2) The findings and corresponding models are meant to be implemented in an electronic and automated system within the EMR. This way, providers do not need to memorize or recall any of the results of the study unless a patient is at high risk of a return visit. Such automated system would include the risk factors contributing to the patient's high risk. And (3) this work provides incremental addition to literature from which other investigators and researchers can build on.

\section{Abbreviations}

AUROC: Area under the receiver operator characteristic curve; ICD-10CM: International Classification of Diseases, Tenth Revision; ED: Emergency department; GVIF: Generalized variance inflation factor

\section{Authors' contributions}

$L E, W F$, and DG conceived of the study. EY, LE, and CR conducted statistical and machine learning development. WF and DG provided clinical interpretation and guidance. All authors contributed to the drafting of the manuscript and its revisions. The author(s) read and approved the final manuscript

\section{Funding}

None

\section{Availability of data and materials}

The datasets used and/or analyzed during the current study are available from the corresponding author on reasonable request.

\section{Ethics approval and consent to participate}

This study was approved by the CHOC Children's Institutional Review Board (IRB 180857).

\section{Consent for publication}

All authors approve the submission of the article.

\section{Competing interests}

None of the authors have any relevant competing of interest to disclose.

Received: 4 May 2020 Accepted: 4 August 2020

Published online: 14 August 2020

\section{References}

1. Tang N, Stein J, Hsia RY, Maselli JH, Gonzales R. Trends and characteristics of US emergency department visits, 1997-2007. Jama. 2010;304(6):664-70.

2. Lowthian JA, Curtis AJ, Jolley DJ, Stoelwinder JU, MCNeil JJ, Cameron PA. Demand at the emergency department front door: 10-year trends in presentations. Med J Aust. 2012;196(2):128-32.

3. Pines JM, Mullins PM, Cooper JK, Feng LB, Roth KE. National trends in emergency department use, care patterns, and quality of care of older adults in the United States. J Am Geriatr Soc. 2013;61(1):12-7.
4. Davis Z, Zobel CW, Khansa L, Glick RE. Emergency department resilience to disaster-level overcrowding: a component resilience framework for analysis and predictive modeling. J Oper Manag. 2020;66(1-2):54-66.

5. Boyle A, Abel G, Raut P, et al. Comparison of the International Crowding Measure in Emergency Departments (ICMED) and the National Emergency Department Overcrowding Score (NEDOCS) to measure emergency department crowding: pilot study. Emerg Med J. 2016;33(5):307-12.

6. Phillips JL, Jackson BE, Fagan EL, et al. Overcrowding and its association with patient outcomes in a median-low volume emergency department. J Clin Med Res. 2017;9(11):911.

7. Grumbach K, Keane D, Bindman A. Primary care and public emergency department overcrowding. Am J Public Health. 1993;83(3):372-8.

8. Richardson DB. Increase in patient mortality at 10 days associated with emergency department overcrowding. Med J Aust. 2006;184(5):213-6.

9. Trzeciak S, Rivers EP. Emergency department overcrowding in the United States: an emerging threat to patient safety and public health. Emerg Med J. 2003:20(5):402-5.

10. Cowan RM, Trzeciak S. Clinical review: emergency department overcrowding and the potential impact on the critically ill. Crit Care. 2004; 9(3):291.

11. Miro O, Antonio MT, Jimenez S, et al. Decreased health care quality associated with emergency department overcrowding. Eur J Emerg Med Off J Eur Soc Emerg Med. 1999;6(2):105-7.

12. Lerman B, Kobernick MS. Return visits to the emergency department. J Emerg Med. 1987;5(5):359-62.

13. Keith KD, Bocka JJ, Kobernick MS, Krome RL, Ross MA. Emergency department revisits. Ann Emerg Med. 1989;18(9):964-8.

14. Verelst S, Pierloot S, Desruelles D, Gillet J-B, Bergs J. Short-term unscheduled return visits of adult patients to the emergency department. J Emerg Med. 2014:47(2):131-9.

15. Hu K-W, Lu Y-H, Lin H-J, Guo H-R, Foo N-P. Unscheduled return visits with and without admission post emergency department discharge. J Emerg Med. 2012;43(6):1110-8.

16. Wu CL, Wang FT, Chiang YC, et al. Unplanned emergency department revisits within 72 hours to a secondary teaching referral hospital in Taiwan. J Emerg Med. 2010;38(4):512-7. https://doi.org/10.1016/j.jemermed.2008.03. 039.

17. Jiménez-Puente A, Lara-Blanquer A, Arjona-Huertas $J$, et al. Causes of 72 hour return visits to hospital emergency departments. Emergencias. 2015; 27(5):287-93.

18. Rising KL, Padrez KA, O'Brien M, Hollander JE, Carr BG, Shea JA. Return visits to the emergency department: the patient perspective. Ann Emerg Med. 2015;65(4):377-386.e3. https://doi.org/10.1016/j.annemergmed.2014.07.015.

19. Ruttan T, Lawson KA, Piper K, Wilkinson M. Risk factors associated with emergency department return visits following trauma system discharge. Pediatr Emerg Care. 2018;34(3):202-7.

20. Southerland LT, Stephens JA, Robinson S, et al. Head trauma from falling increases subsequent emergency department visits more than other fallrelated injuries in older adults. J Am Geriatr Soc. 2016;64(4):870-4.

21. Ladha KS, Young JH, Ng DK, Efron DT, Haider AH. Factors affecting the likelihood of presentation to the emergency department of trauma patients after discharge. Ann Emerg Med. 2011;58(5):431-7.

22. Kansagara D, Englander $\mathrm{H}$, Salanitro A, et al. Risk prediction models for hospital readmission: a systematic review. Jama. 2011;306(15):1688-98.

23. Ehwerhemuepha L, Pugh K, Grant A, et al. A statistical learning model for unplanned 7-day readmission in pediatrics. Hosp Pediatr. 2019;10(1):43-51.

24. Ehwerhemuepha L, Finn S, Rothman MJ, Rakovski C, Feaster W. A novel model for enhanced prediction and understanding of unplanned 30-day pediatric readmission. Hosp Pediatr. 2018;8(9).

25. Glynn EF, Hoffman MA. Heterogeneity introduced by EHR system implementation in a de-identified data resource from 100 non-affiliated organizations. JAMIA Open. 2019.

26. Heinze $G$, Schemper M. A solution to the problem of separation in logistic regression. Stat Med. 2002;21(16):2409-19.

27. Ehwerhemuepha L, Sok H, Rakovski C. A more powerful unconditional exact test of homogeneity for 2 by c contingency table analysis. J Appl Stat. 2019: $1-11$.

28. O'brien RM. A caution regarding rules of thumb for variance inflation factors. Qual Quant. 2007;41(5):673-90.

29. Boik R. Interactions, partial interactions, and interaction contrasts in the analysis of variance. Psychol Bull. 1979;86(5):1084. 
30. Friedman JH. Greedy function approximation: a gradient boosting machine. Ann Stat. 2001:1189-232.

31. Friedman JH. Stochastic gradient boosting. Comput Stat Data Anal. 2002; 38(4):367-78.

32. Spark A. Apache Spark: lightning-fast cluster computing. URL http//spark apache org. 2016.

33. The Apache Software Foundation. Spark - Python Programming Guide. https://spark.apache.org/docs/latest/api/python/index.html. Published 2019.

34. R Core Team. R: a language and environment for statistical. computing. 2017; https://www.r-project.org/.

35. Python Software Foundation. Python. 2019. www.python.org. Published 2019.

\section{Publisher's Note}

Springer Nature remains neutral with regard to jurisdictional claims in published maps and institutional affiliations.

Ready to submit your research? Choose BMC and benefit from:

- fast, convenient online submission

- thorough peer review by experienced researchers in your field

- rapid publication on acceptance

- support for research data, including large and complex data types

- gold Open Access which fosters wider collaboration and increased citations

- maximum visibility for your research: over $100 \mathrm{M}$ website views per year

At BMC, research is always in progress. 